\title{
Aspernidine A and B, prenylated isoindolinone alkaloids from the model fungus Aspergillus nidulans
}

\author{
Kirstin Scherlach $^{1}$, Julia Schuemann ${ }^{1}$, Hans-Martin Dahse ${ }^{1}$ and Christian Hertweck ${ }^{1,2}$
}

The Journal of Antibiotics (2010) 63, 375-377; doi:10.1038/ja.2010.46; published online 26 May 2010

Keywords: antiproliferative agents; Aspergillus nidulans; cryptic natural products; genome mining; isoindole; polyketides; prenylation

Filamentous fungi produce a multitude of bioactive natural products, which cover a broad range of useful pharmaceutical activities. Many of these compounds were discovered by traditional natural product screening approaches and have found various applications in modern medicine. ${ }^{1,2}$ Through recent whole-genome sequencing projects, however, we become increasingly aware that the biosynthetic potential of microorganisms is much higher than expected. ${ }^{3}$ In many cases, the number of putative biosynthetic genes of fungi and bacteria is not reflected by the metabolic profile observed under laboratory culture conditions. Several gene loci encoding diverse metabolic pathways seem to lack expression in the absence of particular physical or chemical stimuli. ${ }^{4}$ Mining the genome of Aspergillus nidulans for putative biosynthesis gene clusters revealed biosynthetic abilities for the production of up to 28 polyketides and 24 nonribosomally synthesized peptides. ${ }^{5,6}$ However, this abundance of gene clusters clearly outnumbers the known secondary metabolites of this fungus. To gain access to this untapped reservoir of potentially bioactive natural products, various strategies to induce the expression of silent genes have been developed. ${ }^{4,7}$ Important recent examples involve the ectopic expression of a regulatory gene, ${ }^{8}$ the induction of a transcription activator by promotor exchange, ${ }^{9}$ as well as modulation of the epigenetic regulation of biosynthetic genes at the chromatin level. ${ }^{10-13}$ Furthermore, it was shown that the intimate contact between A. nidulans and a soil-dwelling actinomycete may lead to the specific induction of a cryptic polyketide gene cluster. ${ }^{14}$ These strategies resulted in the discovery of a set of novel secondary metabolites, which could not be located by classical screening methods. Another option often preceding genomic approaches is the systematic investigation of the microbial secondary metabolome under various growth conditions. Since the early days of fermentations, it is known that the choice of the cultivation parameters is critical to the number and type of secondary metabolites produced by microorganisms. ${ }^{4}$ Thus, the formation of cryptic natural products can up to a certain extent be triggered by a systematic variation of standard fermentation para- meters to increase the number of secondary compounds produced in the bacterial or fungal culture. ${ }^{15,16}$ On the basis of the assumption that changing environmental conditions can shift the metabolic profile of an organism, we systematically varied the cultivation parameters to reinvestigate the metabolome of $A$. nidulans. In this study, we report the discovery of two new isoindole alkaloids, aspernidine A (1) and B (2), as an addition to the metabolic data of this important model fungus (Figure 1a).

An A. nidulans extract library was prepared by adjusting 45 different culture conditions (variation of culture media, cultivation period, temperature and oxygen supply) and the metabolic profiles were screened by HPLC-DAD-MS. Investigation of the culture of A. nidulans AXB4A2 grown at elevated temperature $\left(37^{\circ} \mathrm{C}\right)$ and increased orbital shaking (200 r.p.m.) in malt medium and uridine/ $p$-aminobenzoate supplementation revealed the production of two potentially new metabolites with a molecular weight of $\mathrm{m} / z 399$ and $m / z$ 385, respectively. Similar UV spectra and similar MS ${ }^{n}$ fragmentation patterns suggested that both compounds are closely related. From an upscaled culture (141), the compounds were isolated and their structures elucidated by one- and two-dimensional NMR and MS measurements. For compound 1, a molecular formula of $\mathrm{C}_{24} \mathrm{H}_{33} \mathrm{NO}_{4}$ was established by HRESI-MS analysis. The ${ }^{13} \mathrm{C}$ NMR spectrum displayed $24 \mathrm{C}$-atoms, which were assigned to four methyl, one methoxy, six methylene, four $\mathrm{sp}^{2}$-hybridized and nine quaternary carbons by DEPT measurements. The structure of the farnesyl side chain was deduced from characteristic $\mathrm{H}, \mathrm{H}-\mathrm{COSY}$ and $\mathrm{HMBC}$ correlations (Figure $1 \mathrm{~b}$ ). HMBC coupling of the methylene protons $\mathrm{H}-\mathrm{1}^{\prime}$ to a quaternary carbon at 137.3 p.p.m. indicated O-prenylation of the aromatic system. $\mathrm{H}, \mathrm{H}-\mathrm{COSY}$ correlation of $\mathrm{H}-2$ and $\mathrm{H}-3, \mathrm{HMBC}$ couplings of $\mathrm{H}-3$ and $\mathrm{C}-1, \mathrm{C}-3 \mathrm{a}$ and $\mathrm{C}-4$, as well as an $\mathrm{HMBC}$ coupling of $4-\mathrm{OH}$ and $\mathrm{C}-3 \mathrm{a}$, which could only be observed when measuring at decreased temperature $\left(7^{\circ} \mathrm{C}\right)$ revealed the phthalimidine substructure. HMBC coupling of $\mathrm{H}-1^{\prime \prime}$ and C-6 established the

${ }^{1}$ Leibniz Institute for Natural Product Research and Infection Biology, HKI, Department of Biomolecular Chemistry and Department of Infection Biology, Jena, Germany and 2Friedrich Schiller University, Jena, Germany

Correspondence: Professor C Hertweck, Department of Biomolecular Chemistry, Leibniz Institute for Natural Product Research and Infection Biology, HKI, Beutenbergstr. 11a, Jena 07745, Germany.

E-mail: christian.hertweck@hki-jena.de

Received 9 March 2010; revised 19 March 2010; accepted 11 April 2010; published online 26 May 2010 
<smiles>[Y][Z](C)=CCC/C(C)=C/CC/C(C)=C/COc1c(O)cc2c(c1O)CNC2=O</smiles>

b

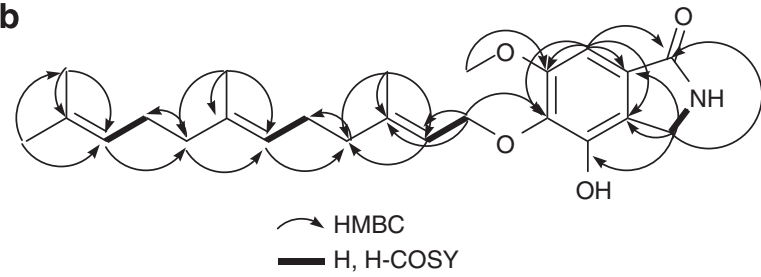

c<smiles>[R]Oc1cc2c(c(OC)c1C)CN([R])C2=O</smiles>

Figure 1 (a) Structures of aspernidine A (1) and B (2); (b) key HMBC and $\mathrm{H}, \mathrm{H}$-COSY correlations for $\mathbf{1}$; (c) structures of biogenetically related fungal metabolites.

position of the methoxy substituent. The structurally related compound 2 has a molecular formula of $\mathrm{C}_{23} \mathrm{H}_{31} \mathrm{NO}_{4}$ (deduced from HRESI-MS), which suggested the lack of a methyl group. One- and two-dimensional NMR data confirmed this assumption. Although a couple of isoindole derivatives have been isolated from fungal sources, the production of such metabolites has not yet been reported for $A$. nidulans. Zinnimidine (3) and porritoxin (4) were isolated from Alternaria porri, ${ }^{17-19}$ 6-hydroxy-4-methoxy-5-methylphthalimidine (5) from cultures of Aspergillus silvaticus ${ }^{20}$ and duricaulic acid (6) from Aspergillus duricaulis. ${ }^{21}$ Several isoindoles are also produced by Stachybotrys spp.22 (Figure 1c). Notably, from Aspergillus rugulosus, a species closely related to $A$. nidulans, two aromatic dialdehydes, asperugins $A(7)$ and $B(8)$, were isolated, which show the same substitution pattern as the aromatic moiety of aspernidine $\mathrm{A}$ and $\mathrm{B} .{ }^{23}$ The occurrence of these compounds in the same genus as well as the isolation of $\mathbf{9}$, an oxo analog of zinnimidine, and the hydroxymethylene-substituted zinniol $(\mathbf{1 0})^{24}$ suggest a common metabolic pathway for isoindole formation. It is well conceivable that the pathway is initiated by the formation of orsellinic acid or, more likely, the corresponding aldehyde by a nonreducing polyketide synthase. Ammonia nitrogen would be trapped from an intermediary aldehyde, and oxidoreductive and condensation steps would lead to the isoindolinone core. Hydroxylation, methylation and $O$-prenylation of the molecules represent the final steps of the biosynthetic process, the latter of which are often associated with increased biological activity. In a primary bioactivity screening, we found that 1 and 2 possess moderate antiproliferative activities (L-929 $\mathrm{GI}_{50} 35.8 \mu \mathrm{m}$ (1) and $39.5 \mu \mathrm{M}$ (2); K-562 $\mathrm{GI}_{50} 34.3 \mu \mathrm{M}$ (1) and $39.5 \mu \mathrm{M}$ (2), respectively) and even lower cytotoxicity (HeLa CC $5094.0 \mu \mathrm{m}$ (1) and $65.5 \mu \mathrm{M}$ (2)).

In conclusion, motivated by genomic data and through systematically varying the culture conditions, we have discovered two novel alkaloids from the model organism $A$. nidulans. Isolation of these metabolites and their characterization revealed the structures of two unusual prenylated isoindolinones, aspernidine $\mathrm{A}$ and $\mathrm{B}$, which show moderate antiproliferative effects against various tumor cell lines. Our findings are thus an important addition to the body of knowledge on bioactive compounds from A. nidulans and further highlight the largely overlooked biosynthetic potential of this important model organism.

\section{MATERIALS AND METHODS}

NMR spectra were recorded on Bruker Avance DRX 500 and DPX 300 instruments (Bruker Biospin GmbH, Rheinstetten, Germany). Spectra were referenced to the residual solvent signals. High-resolution mass spectra were measured with a TSQ Quantum AM Ultra (Thermo Electron, Bremen, Germany). IR spectra were obtained with a Jasco FT/IR 4100 spectrometer (Jasco International Co. Ltd., Tokyo, Japan). Flash chromatography was performed using a CombiFlash RETRIEVE system by Teledyne Isco (Lincoln, NE, USA) with $120 \mathrm{~g}$ RediSep silica columns. Analytical HPLC was performed on a Shimadzu HPLC system (Shimadzu, Kyoto, Japan) consisting of an autosampler, high-pressure pumps, column oven and DAD. HPLC conditions: C18 column (Eurospher 100-5 250 $\times 4.6 \mathrm{~mm}$, Knauer, Berlin, Germany) and gradient elution (MeCN/0.1\% TFA 0.5/99.5 in $30 \mathrm{~min}$ to MeCN/0.1\% TFA $100 / 0, \mathrm{MeCN} 100 \%$ for $10 \mathrm{~min}$ ), flow rate $1 \mathrm{ml} \mathrm{min}^{-1}$.

\section{Fungal culture, extraction and isolation of compounds}

A. nidulans $\mathrm{AXB} 4 \mathrm{~A} 2^{25}$ was cultured on malt medium (malt extract $20 \mathrm{gl}^{-1}$, yeast extract $2 \mathrm{gl}^{-1}$, glucose $\left.10 \mathrm{gl}^{-1},\left(\mathrm{NH}_{4}\right)_{2} \mathrm{HPO}_{4}, 0.5 \mathrm{gl}^{-1}\right)$ supplemented with $1 \mathrm{M}$ uridine solution $\left(4 \mathrm{ml}^{-1}\right)$ and $p$-aminobenzoic acid $\left(3 \mu \mathrm{g} \mathrm{ml}^{-1}\right)$ at $37^{\circ} \mathrm{C}$ and 200 r.p.m. for 7 days.

The entire fermentation broth was exhaustively extracted with ethyl acetate, the combined extracts were concentrated under reduced pressure. The crude extract was separated by flash chromatography on silica gel using $\mathrm{CHCl}_{3} /$ $\mathrm{MeOH}$ mixtures of increasing polarity as eluents (flow rate $35 \mathrm{ml} \mathrm{min}^{-1}$ ). Metabolite-containing fractions were further purified by size exclusion chromatography on Sephadex LH-20 (Pharmacia Fine Chemicals, Uppsala, Sweden) (eluent $\mathrm{MeOH}$ ) and preparative HPLC (column: Eurospher 100-5 250×20 (Knauer), gradient mode with $\mathrm{MeCN} / \mathrm{H}_{2} \mathrm{O}: 1 \% \mathrm{MeCN}$ to $83 \% \mathrm{MeCN}$ in $30 \mathrm{~min}$, then $83 \% \mathrm{MeCN}$ for $10 \mathrm{~min}$, flow rate $12 \mathrm{ml} \mathrm{min}^{-1}$, UV detection $216 \mathrm{~nm}$ ).

\section{Physicochemical data}

Aspernidine A (1). White amorphous solid. ${ }^{1} \mathrm{H}$ NMR $(300 \mathrm{MHz})$ and ${ }^{13} \mathrm{C}$ $\mathrm{NMR}\left(75 \mathrm{MHz}\right.$ ) in $\mathrm{CDCl}_{3}$ (Table 1). IR Vmax (ATR, solid) $\mathrm{cm}^{-1} 3247,2923$, 2855, 1698, 1684, 1671, 1624, 1604, 1478, 1456, 1436, 1358, 1260, 1213, 1119, 1026, 770. UV (DAD) $\lambda_{\max }=216,258 \mathrm{~nm}$. (+)-ESI-MS $m / z 422[\mathrm{M}+\mathrm{Na}]^{+}, m / z$ $400[\mathrm{M}+\mathrm{H}]^{+}$. HRESI-MS: $m / z[\mathrm{M}+\mathrm{Na}]^{+}=422.2315$ (calcd for $\mathrm{C}_{24} \mathrm{H}_{33} \mathrm{NO}_{4} \mathrm{Na}$ 422.2307).

Aspernidine B (2). White amorphous solid. ${ }^{1} \mathrm{H}$ NMR $(300 \mathrm{MHz})$ and ${ }^{13} \mathrm{C}$ NMR $(75 \mathrm{MHz})$ in $\mathrm{CD}_{3} \mathrm{OD}$ (Table 1). IR Vmax (ATR, solid) $\mathrm{cm}^{-1} 3218,2963$, 2922, 2847, 1792, 1656, 1635, 1479, 1454, 1357, 1310, 1217, 1091, 1034, 979, 
Table 1 NMR data for aspernidine A (1) $\left(\mathrm{CDCl}_{3}\right)$ and $\mathrm{B}(2)\left(\mathrm{CD}_{3} \mathrm{OD}\right)$

\begin{tabular}{|c|c|c|c|c|}
\hline \multirow[b]{2}{*}{ Position } & \multicolumn{2}{|l|}{1} & \multicolumn{2}{|l|}{2} \\
\hline & $\delta_{H}($ p.p.m. $)(J(H z])$ & $\delta_{C}($ p.p.m. $)$ & $\delta_{H}($ p.p.m. $)(J(H z))$ & $\delta_{C}($ p.p.m.) \\
\hline 1 & - & 171.8 & - & 174.2 \\
\hline 2 & $6.82 \mathrm{br} \mathrm{s}$ & - & ND & - \\
\hline 3 & $4.33 \mathrm{~s}$ & 42.8 & $4.24 \mathrm{~s}$ & 44.1 \\
\hline $3 a$ & - & 122.5 & - & 123.8 \\
\hline 4 & - & 144.9 & - & 147.6 \\
\hline $4-\mathrm{OH}$ & $6.16 \mathrm{br} \mathrm{s}$ & - & ND & - \\
\hline 5 & - & 137.3 & - & 138.6 \\
\hline 6 & - & 153.5 & - & 153.2 \\
\hline 7 & $6.99 \mathrm{~s}$ & 98.6 & $6.78 \mathrm{~s}$ & 102.5 \\
\hline $7 a$ & - & 127.6 & - & 128.5 \\
\hline $1^{\prime}$ & $4.65 \mathrm{~d}(7.5)$ & 69.6 & $4.68 d(7.4)$ & 69.6 \\
\hline $2^{\prime}$ & $5.49 \mathrm{t}(7.5)$ & 119.1 & $5.53 \mathrm{t}(7.4)$ & 121.2 \\
\hline $3^{\prime}$ & - & 144.1 & - & 143.7 \\
\hline $4^{\prime}$ & $2.05 \mathrm{~m}^{\mathrm{a}}$ & 39.6 & $2.00 \mathrm{~m}^{\mathrm{a}}$ & 40.8 \\
\hline $5^{\prime}$ & $2.05 \mathrm{~m}^{\mathrm{a}}$ & 26.3 & $2.00 \mathrm{~m}^{\mathrm{a}}$ & 27.5 \\
\hline $6^{\prime}$ & $5.06 \mathrm{~m}^{\mathrm{a}}$ & 123.5 & $5.05 \mathrm{~m}^{\mathrm{a}}$ & 125.2 \\
\hline $7^{\prime}$ & - & 135.6 & - & 136.2 \\
\hline $8^{\prime}$ & $1.95 \mathrm{~m}$ & 39.6 & $1.96 \mathrm{~m}^{\mathrm{a}}$ & 40.8 \\
\hline $9^{\prime}$ & $2.05 \mathrm{~m}^{\mathrm{a}}$ & 26.7 & $2.00 \mathrm{~m}^{\mathrm{a}}$ & 27.8 \\
\hline $10^{\prime}$ & $5.06 \mathrm{~m}^{\mathrm{a}}$ & 124.3 & $5.05 \mathrm{~m}^{\mathrm{a}}$ & 125.4 \\
\hline $11^{\prime}$ & - & 131.3 & - & 132.1 \\
\hline $12^{\prime}$ & $1.65 \mathrm{~s}$ & 25.7 & $1.65 \mathrm{~s}$ & 25.9 \\
\hline $13^{\prime}$ & $1.57 \mathrm{~s}^{\mathrm{a}}$ & 17.7 & $1.58 \mathrm{~s}^{\mathrm{a}}$ & 17.7 \\
\hline $14^{\prime}$ & $1.56 \mathrm{~s}^{\mathrm{a}}$ & 16.0 & $1.55 \mathrm{~s}^{\mathrm{a}}$ & 16.0 \\
\hline $15^{\prime}$ & $1.63 \mathrm{~s}$ & 16.4 & $1.58 \mathrm{~s}^{\mathrm{a}}$ & 16.4 \\
\hline $1^{\prime \prime}$ & $3.90 \mathrm{~s}$ & 56.2 & - & - \\
\hline
\end{tabular}

Abbreviation: ND, not detected.

apartial overlapping of signals.

771. UV (DAD) $\lambda_{\max }=218,258 \mathrm{~nm}$. (+)-ESI-MS $m / z 386[\mathrm{M}+\mathrm{H}]^{+}, m / z 408$ $[\mathrm{M}+\mathrm{Na}]^{+}$. HRESI-MS: $\mathrm{m} / z \quad[\mathrm{M}+\mathrm{H}]^{+}=386.2321$ (calcd for $\mathrm{C}_{23} \mathrm{H}_{32} \mathrm{NO}_{4}$ 386.2326)

\section{CONFLICT OF INTEREST}

The authors declare no conflict of interest.

\section{ACKNOWLEDGEMENTS}

We thank A Perner and F Rhein for MS and NMR measurements, respectively, and M-G Schwinger for assistance in strain cultivation. The financial support provided by the Leibniz Gemeinschaft (Pakt für Wissenschaft und Innovation) is gratefully acknowledged.
1 Newman, D. J. \& Cragg, G. M. Natural products as sources of new drugs over the last 25 years. J. Nat. Prod. 70, 461-477 (2007).

2 Bérdy, J. Bioactive microbial metabolites. J. Antibiot. 58, 1-26 (2005).

3 Hertweck, C. Hidden biosynthetic treasures brought to light. Nat. Chem. Biol. 5, 450-452 (2009).

4 Scherlach, K. \& Hertweck, C. Triggering cryptic natural product biosynthesis in microorganisms. Org. Biomol. Chem. 7, 1753-1760 (2009).

5 Galagan, J. E. et al. Sequencing of Aspergillus nidulans and comparative analysis with A. fumigatus and $A$. oryzae. Nature 438, 1105-1115 (2005).

6 von Döhren, H. A survey of nonribosomal peptide synthetase (NRPS) genes in Aspergillus nidulans. Fungal Genet. Biol. 46(Suppl 1), S45-S52 (2009).

7 Gross, H. Strategies to unravel the function of orphan biosynthesis pathways: recent examples and future prospects. Appl. Microbiol. Biotechnol. 75, 267-277 (2007).

8 Bergmann, S. et al. Genomics-driven discovery of PKS-NRPS hybrid metabolites from Aspergillus nidulans. Nat. Chem. Biol. 3, 213-217 (2007).

9 Chiang, Y. M. et al. A gene cluster containing two fungal polyketide synthases encodes the biosynthetic pathway for a polyketide, asperfuranone, in Aspergillus nidulans. J. Am. Chem. Soc. 131, 2965-2970 (2009).

10 Bok, J. W. et al. Chromatin-level regulation of biosynthetic gene clusters. Nat. Chem. Biol. 5, 462-464 (2009).

11 Williams, R. B., Henrikson, J. C., Hoover, A. R., Lee, A. E. \& Cichewicz, R. H. Epigenetic remodeling of the fungal secondary metabolome. Org. Biomol. Chem. 6, 1895-1897 (2008).

12 Henrikson, J. C., Hoover, A. R., Joyner, P. M. \& Cichewicz, R. H. A chemical epigenetics approach for engineering the in situ biosynthesis of a cryptic natural product from Aspergillus niger. Org. Biomol. Chem. 7, 435-438 (2009).

13 Fisch, K. M. et al. Chemical induction of silent biosynthetic pathway transcription in Aspergillus niger. J. Ind. Microbiol. Biotechnol. 36, 1199-1213 (2009).

14 Schroeckh, V. et al. Intimate bacterial-fungal interaction triggers biosynthesis of archetypal polyketides in Aspergillus nidulans. Proc. Natl Acad. Sci. USA 106, 14558-14563 (2009).

15 Bode, H. B., Bethe, B., Hofs, R. \& Zeeck, A. Big effects from small changes: possible ways to explore nature's chemical diversity. Chembiochem 3, 619-627 (2002).

16 Scherlach, K. \& Hertweck, C. Discovery of aspoquinolones A-D, prenylated quinoline-2one alkaloids from Aspergillus nidulans, motivated by genome mining. Org. Biomol. Chem. 4, 3517-3520 (2006).

17 Suemitsu, R., Ohnishi, K., Morikawa, Y. \& Nagatomo, S. Zinnimidine and 5-(3',3'dimethylallyloxy)-7-methoxy-6-methylphthalide from Alternaria porri. Phytochemistry 38, 495-497 (1995).

18 Horiuchi, M., Maoka, T., Iwase, N. \& Ohnishi, K. Reinvestigation of structure of porritoxin, a phytotoxin of Alternaria porri. J. Nat. Prod. 65, 1204-1205 (2002).

19 Horiuchi, M. et al. A novel isoindoline, porritoxin sulfonic acid, from Alternaria porri and the structure-phytotoxicity correlation of its related compounds. Biosci. Biotechnol. Biochem. 67, 1580-1583 (2003).

20 Kawahara, N., Nozawa, K., Nakajima, S., Udagawa, S. \& Kawai, K. Studies on fungal products. XVI. New metabolites related to 3-methylorsellinate from Aspergillus silvaticus. Chem. Pharm. Bull. 36, 398-400 (1988).

21 Achenbach, H., Muhlenfeld, A., Kohl, W. \& Brillinger, G. U. Metabolic products of microorganisms. 31. Duricaulic acid, a new natural product of the phthalimidine type from Aspergillus duricaulis. Z. Naturforsch. B 40, 1219-1225 (1985).

22 Nozawa, Y., Ito, M., Sugawara, K., Hanada, K. \& Mizoue, K. Stachybotrin C and parvisporin, novel neuritogenic compounds. II. Structure determination. J. Antibiot. 50, 641-645 (1997).

23 Ballantine, J. A., Hassall, C. H. \& Jones, G. The biosynthesis of phenols. IX. Asperugin, a metabolic product of Aspergillus rugulosus. J. Chem. Soc. [Perkin 1] 4672-4678 (1965).

24 Stierle, A., Hershenhorn, J. \& Strobel, G. Zinniol-related phytotoxins from Alternaria cichorii. Phytochemistry 32, 1145-1149 (1993).

25 Weidner, G., d'Enfert, C., Koch, A., Mol, P. C. \& Brakhage, A. A. Development of a homologous transformation system for the human pathogenic fungus Aspergillus fumigatus based on the pyrG gene encoding orotidine $5^{\prime}$-monophosphate decarboxylase. Curr. Genet. 33, 378-385 (1998). 